\title{
AUTORREGULAÇÃO REGULADA E O COMBATE A MERCANTILIZAÇÃO DOS DIREITOS HUMANOS
}

\section{Jéssica Cindy Kempfer ${ }^{1}$}

Resumo: Com os processos de globalização e das novas tecnologias de informação, começam a surgir uma série de atores políticos que passam a exercer grande força política, econômica e jurídica, afetando diretamente os direitos humanos. A partir disso, pretende-se analisar a possibilidade de aplicação da técnica da autorregulação regulada como forma de garantir a proteção dos direitos humanos no ambiente das empresas transnacionais. Para isso, utilizandose o método dedutivo, se abordará os elementos básicos do processo de globalização, o surgimento de novos agentes supraestatais e a violação dos direitos humanos na lógica de mercado, para, por fim tratar da autorregulação regulada.

Palavras-chave: Transnacionalismo. Direitos Humanos. Autorregulação regulada. Globalização. Agentes supraestatais.

\section{REGULATED SELF-REGULATION AND THE BATTLE AGAINST HUMAN RIGHTS MERCHANTABILITY}

\begin{abstract}
Abstract: With the processes of globalization a series of political actors have exerted great political, economic and legal force as well as affected human rights by framing them in a market logic. From this, we intend to analyze the possibility of applying the technique of regulated self-regulation to guarantee the protection of human rights in the environment of transnational corporations. To do so, using the deductive method, we will address the basic elements of the globalization process, the emergence of new suprastate agents and the violation of human rights in the market logic, to finally approach the regulated self-regulation technique.
\end{abstract}

Keywords: Transnationalism. Human rights. Regulated self-regulation. Globalization. Suprastate agents.

\section{INTRODUÇÃO}

Com os processos de globalização e das novas tecnologias de informação, começam a surgir desigualdades entre a fortaleza do direito global e a fragilidade dos ordenamentos

\footnotetext{
${ }^{1}$ Especialista em Direito Tributário Empresarial e Mestra em Direito, Democracia e Sustentabilidade pela Faculdade Meridional - IMED. Professora da Universidade Luterana do Brasil - ULBRA, Campus Carazinho. RS. Currículo Lattes: http://lattes.cnpq.br/2340640196887918 - E-mail: jessicakempfer@ gmail.com.
} 
Jéssica Cindy Kempfer

nacionais receptores da atividade econômica. Assim, começam a surgir uma série de atores políticos que não estão adstritos apenas as fronteiras de um único Estado.

As empresas transnacionais passam a exercer grande força política, econômica e jurídica, afetando diretamente os direitos humanos, que passam a seguir a lógica de mercado. Interesses públicos, coletivos e privados se compõem de modo variado, convergido ou divergido em relação às posições de força contratual para as contrapartidas oferecidas.

A partir disso, o objetivo do presente estudo é analisar a possibilidade de a técnica da autorregulação regulada se apresentar como uma forma de combate a mercantilização dos direitos humanos ${ }^{2}$, que se mostra como resultado da globalização econômica. Essa nova forma de autorregulação associa tanto a autorregulação (privada) e a regulação (pública), onde os entes privados no processo de regulação ficariam subordinados aos interesses públicos estabelecidos pelo Estado.

Para tanto, utilizando-se o método dedutivo para a pesquisa, na primeira parte aborda-se os elementos básicos do processo de globalização e o surgimento de novos agentes supraestatais. Depois, trata-se da violação dos direitos humanos em uma premissa que encaixa com a lógica de mercado, onde o poder econômico e político sejam um eixo cotidiano que permite as empresas transnacionais influenciar diretamente os responsáveis dos Estados em suas estruturas e organismos. Por fim, trata-se da autorregulação regulada como técnica para minimizar a afetação dos direitos humanos e dos bens coletivos por alguns agentes transnacionais.

\section{UMA NOVA ZONA INSTITUCIONAL DE AGENTES PRIVADOS}

A globalização e as novas tecnologias da comunicação e informação proporcionam que uma variedade de atores políticos locais entrem em arenas internacionais que antes eram exclusivas dos Estados nacionais. As pessoas físicas e jurídicas não estão mais adstritas às

\footnotetext{
${ }^{2}$ Onde os direitos humanos são encarados pela lógica mercantil e do lucro do empreendimento.
} 
fronteiras de um único Estado. A sociedade vem se transformando e com isso o papel exercido pelos seus atores, tanto estatais como não estatais, vem se alterando.

São inúmeras as propostas para definição da globalização como um evento de integração global. De uma forma geral, este fenômeno implica em uma intensificação de relações sociais e em uma atenuação da distância territorial entre os acontecimentos ${ }^{3}$ e que, dessa forma, está intimamente ligada a aceleração de uma economia mundial e de um universalismo de mercado.

A globalização trata-se, em síntese, de uma integração sistêmica da economia em um nível transnacional, alicerçada na mercantilização do conhecimento, na eficiência, na produtividade e deflagrada pela subsequente ampliação das redes empresariais e financeiras, em uma escala global, atuando cada vez mais independente dos controles políticos e jurídicos de nível nacional. ${ }^{4}$

Desde a última década, o conceito de globalização tem sido utilizado para descrever um complexo conjunto de processos interligados. Embora não se possa reduzir a globalização apenas ao fenômeno econômico, o mercado se mostra como principal motivador das relações interestatais, como um dos elementos e características da globalização.

\begin{abstract}
A sociedade mundial, que tomou uma nova forma no curso da globalização - e isto não apenas em sua dimensão econômica -, relativiza e interfere na atuação do Estado nacional, pois uma imensa variedade de lugares conectados entre si cruza suas fronteiras territoriais, estabelecendo novos círculos sociais, redes de comunicação, relações de mercado e formas de convivência. (BECK, 1999, p.18)
\end{abstract}

O colapso do capitalismo mercantilista ou concorrencial, no final da década de XX, seguido de uma grande depressão, levaram a economia a mudar em um ritmo mais rápido

3 “A globalização pode assim ser definida como a intensificação das relações sociais em escala mundial, que ligam localidades distantes de tal maneira que acontecimentos locais são modelados por eventos ocorrendo a muitas milhas de distância e vice-versa. Este é um processo dialético porque tais acontecimentos locais podem se deslocar numa direção anversa às relações muito distanciadas que os modelam. A transformação local é tanto uma parte da globalização quanto a extensão lateral das conexões sociais através do tempo e do espaço.” (GIDDENS, 1991, p 111).

4 Quando se fala em globalização tem de se ter em mente processos intensos e complexos que geram transformações. Há de pensar em um protagonismo do direito privado onde “... em face da economia mundial, a par do fenômeno das comunicações velozes, a Soberania Estatal perde sua substância." (CRUZ, 2011. p. 88.) 
Jéssica Cindy Kempfer

(FARIA, 2004. p. 14). A economia contemporânea, que surgiu a partir de então, destacou-se por seu aspecto global. Nesta, os principais fatores de produção apresentam uma maior taxa de interdependência e de integração. Os mercados expandem-se, além dos limites territoriais, e estimulam a circulação das economias pessoais em escala mundial (ZOLO, 2010, p. 31.).

A intervenção desse sistema na economia está consubstanciado no que se convém chamar de globalização econômica, um fenômeno multifacetado que exerce uma forte pressão para a desregulação de uma série de mercados, setores econômicos e fronteiras nacionais, assim como para a privatização das empresas e funções do setor público (SASSEN, 2015). Esse fenômeno acarreta uma diminuição generalizada da importância estatal e, nessa nova ordem socioeconômica, o direito positivo enfrenta dificuldades crescentes na edição de normas.

O comércio não é mais local, é global. A burguesia contemporânea é composta por empresas que atuam em todo o mundo e não têm suas fronteiras dentro de um Estado, circulam com seus produtos em vários Estados. Da mesma forma que na baixa Idade Média, precisa-se de regras, previsíveis que possibilitem modelos de negócios aplicáveis em todo o mundo, com sistemas de solução de controvérsias que protejam seus investimentos. Para isso, é necessário criar estruturas globais de produção, execução e aplicação das regras jurídicas (VARELLA, 2013).

O fenômeno da globalização econômica vem criando uma forma de direito global composto por uma variedade de sistemas normativos parciais e autônomos para a administração de setores especializado, que envolve, em um só tempo, integração e fragmentação. As empresas privadas passam a, cada vez mais, substituir o Estado como ator principal e a criar uma ordenação socioeconômica diferenciada. A globalização vem se mostrando como poder do capital global para limitar os estados nacionais e obriga-los a adotar determinadas políticas (SASSEN, 2015).

Nesse contexto, cada vez mais as empresas privadas vem, progressivamente, substituindo o Estado como ator principal, criando algo diferenciado em termos de ordenação socioeconômica e regulação político-administrativa (FARIA, 2004). Existe uma maior mobilidade geográfica e descentralizada da produção econômica, as empresas antes 
multinacionais passam a ser transnacionais, que se desvinculam cada vez mais de seu país de origem e instalam suas unidades produtivas em diferentes pontos, passando a fabricar e a vender seus produtos para o planeta como um todo.

Os atores privados expandem sua atuação pelo cenário internacional e desconhecem as tradicionais fronteiras estatais, chamam para si um protagonismo que antes era exercido pelos Estados. Estes atores que interagem através das fronteiras nacionais, em um tipo de vinculação extra-estatais, são tratados como atores transnacionais ${ }^{5}$. Eles atuam em um ambiente onde a política estatal exerce pouca ou nenhuma capacidade regulatória.

Esse novo processo pode ser interpretado, em termos da desconexão incipiente entre autoridade exclusiva, sobre o território e as pessoas que costumavam ser associadas ao Estado nacional. A intensidade crescente de transações entre as grandes cidades tem criado uma forma de organização transfronteiriça estratégica em formato de rede global (SASSEN, 2010).

O ponto fundamental nessa configuração é o enfraquecimento da autoridade formal exclusiva dos Estados sobre o território nacional. Isso facilita a ascensão de espaços e atores subnacionais e transnacionais ${ }^{6}$ e gera a possibilidade de novas formas de poder e política em diversos níveis.

A proliferação de sistemas autorregulados é evidente em setores dominados por grandes empresas transnacionais (SASSEN, 2006). Esta tendência indica que o sistema econômico global precisa de governança, embora de um tipo diferente, e que os Estados cada vez mais são menos competentes para abordar alguns pontos dessa nova organização de poder.

As instituições transnacionais apontam uma mudança de autoridade do público para o privado quando se trata de comandar e economia global. Elas também modificam a capacidade normativa do Estado a este respeito, levantando questões sobre a soberania do Estado e a governança dos processos econômicos globais.

5 Compreende-se por empresa transnacional a entidade que não possui personalidade jurídica própria no sentido jurídico-positivo, sendo composta por uma empresa sede e unidades filiais constituídas nos mais diversos países de acordo com a nacionalidade. (BAPTISTA, 1987. p. 17.)

6 A inércia do Estado permite ou, até mesmo, impõe que a iniciativa privada fixe padrões normativos. 
Jéssica Cindy Kempfer

Juntamente com estas empresas, surgiram importantes mecanismos de governança cuja autoridade não está centrada no Estado. Existem vários agentes privados, com bastante ou pouca influência, que atuam sob a perspectiva dessa nova ordem normativa que perpassa por diversos Estados e territórios.

A produção normativa se redimensiona, em termos de produção e regulação, para que possa oferecer respostas mais rápidas do que àquelas apresentada pelo Estado. Passa-se a um exercício de poder hegemônico das mais diversas naturezas que institui instrumentos de governança global ante a redução do Estado (STAFFEN, 2015).

O poder estatal perde a sua centralidade. Os organismos transnacionais e supranacionais se estruturam. O Estado moderno não é mais o centro único e soberano do poder. É inegável a interdependência intensificada entre os Estados nas relações internacionais (VIVIANI, 2014).

Os novos paradigmas do Estado colocam em discussão todas as noções, temas e problemas da relação público-privada. Com o alargamento das fronteiras entre público e privado e com essa mudança estrutural dos conceitos, não se pode mais manter imutáveis os dogmas e códigos de referência da doutrina jurídica tradicional. A ordem jurídica global, passa a ser essencialmente constituída por linhas horizontais entre as agências nacionais, globais e autoridades. É um sistema amplamente baseado em cooperação tanto em nível interestadual quanto no nível global (CASSESE, 2006).

A cooperação entre as autoridades nacionais é um elemento essencial do sistema transnacional. As manifestações concretas deste componente são os comitês deliberativos e consultivos de organizações internacionais e acordos de reconhecimento mútuo (CASSESE, 2006).

Esse pluralismo jurídico, ocorrido com o surgimento de novos agentes supraestatais, acaba seguindo uma lógica de mercado: do máximo benefício em menos tempo. Daí que a fusão do poder econômico e político permite às empresas transnacionais influenciar diretamente estruturas e organismos estatais, o que vem gerando uma série de violações dos direitos humanos e laborais. 


\section{A MERCANTILIZAÇÃO DOS DIREITOS HUMANOS}

A globalização econômica no modelo neoliberal é o espaço onde se articula um novo modelo de empresa ajustada a novos tipos de obrigações. Esse novo sistema de regulação das empresas transnacionais requer uma reflexão sobre os direitos humanos.

Os direitos humanos constituem o principal desafio para a humanidade nos primórdios do século XXI. Os limites impostos ao longo da história pelas propostas do liberalismo político e econômico exigem uma reformulação geral que os aproximem da problemática pela qual se passa (FLORES, 2009).

A Declaração Universal dos Direitos Humanos estabelece, em seu artigo 25, que toda pessoa tem direito a um padrão de vida capaz de assegurar a si e a sua família saúde e bemestar. Contudo, os interesses coletivos das populações atingidas não são ouvidos (CASSESE, 2006).

Os direitos humanos e trabalhistas não são vinculantes para as empresas transnacionais e sim negociados em sede contratual, em atividades que respeitam apenas a lógica da negociação. Assim, se torna menos clara a distinção entre público e privado. Interesses públicos, coletivos e privados se compõem de modo variado, convergido ou divergido em relação às posições de força contratual para as contrapartidas oferecidas.

A disputa entre o público e o privado, entre o interesse geral e individual, se transforma nos interesses particulares das empresas. O eixo central é a consagração do individuo-sujeito, que exige o desaparecimento de todos os atores políticos coletivos, como o Estado, em benefício de somente a entidade comum concebível, de uma sociedade de indivíduos livres e autossuficientes sem mais obrigações do que as consigo mesmo.

As boas práticas ficam submissas ao modelo econômico, mas o maior problema reside, não tanto na eficácia das mesmas, mas na desigualdade. Essa ideia tão elementar nos permite questionar os valores sobre os quais se constroem o sistema capitalista e o conceito de democracia.

A divisão da riqueza, a subordinação do individual ao coletivo e os limites do crescimento econômico são categorias que necessitam voltar ao centro dos debates em torno 
Jéssica Cindy Kempfer

da ética econômica. É evidente que a falta de regras é o que levou, entre outras coisas, ao mundo das finanças a extremos (ZUBIZARRETA, 2009).

A cidadania se substitui por consumidores, a lei pelo contrato assimétrico, as normas públicas por acordos privados e as regulações de direitos laborais e sociais por privatizações e desregulações. O binômio democracia-desenvolvimento humano está sendo substituído por preferencias de mercado ((ZUBIZARRETA, 2009).

Se tem optado por estabilizar os mercados financeiros em lugar de apoiar as estratégias pela reconstrução do estado de bem-estar. Já as medidas a favor da cidadania se mostram cada vez mais escassas e de muito curto alcance.

O uso continuado da dupla moral é o discurso que fundamenta o modelo neoliberal e sobre o que se assente parte dos valores da ética empresarial. Se mercantiliza a liberdade e se subordina os princípios de igualdade e de solidariedade aos interesses das classes dominantes.

Existe uma vinculação da ética empresarial com o aumento de benefícios para as empresas. Seus objetivos são buscar preços competitivos. Se considera que a ética empresarial parte da ética econômica e social e seus contornos delimitam os valores e os limites sobre os que se deve desenvolver o mercado.

A realidade dos mecanismos de mercado não está ligada a convicção do direito de estabelecer um novo equilíbrio entre mercado e democracia e sim a redução das políticas públicas, a privatização, a desregulamentação e a criação de regras para favorecimento das atividades econômicas das empresas transnacionais.

Assim nos espaços redimensionados pela globalização não há como se pensar em livre comércio sem mensurar suas consequências humanas. Não apenas conflitos globais carecem de referentes humanistas no seu trato, mas também conflitos setorizados precisam receber atenção transnacional materializadas no Direito Global com apoio de instrumentos efetivos de governança, transcendendo a tradicional compreensão do humanismo na incidência das experiências traumáticas de crimes contra a humanidade (STAFFEN, 2015).

Para redefinir novos valores universais é necessário passar por propostas que modifiquem as regras atuais. É preciso romper com alguns princípios do chamado consenso 
de Washington, em especial, a equiparação automática do crescimento econômico com desenvolvimento humano e a desregulamentação progressiva das leis trabalhistas.

É importante situar os direitos humanos como um eixo ético, político e jurídico das relações internacionais e nacionais já que, em outras questões, dispõem de uma ampla bagagem jurídico internacional. Contudo a unilateralidade nas relações internacionais, a força como instrumento para a resolução de conflitos e a subordinação dos direitos civis e políticos às regras de mercado tem sido o modo de funcionamento. A globalização não está implicando em uma construção de um direito humano universal, mas em uma comercialização e relativização desses direitos.

As sociedades democráticas ocidentais estão há muito tempo anestesiadas por uma nova ideologia caracterizada pelo consumismo, pelo individualismo e pela especulação. Só se mostram preocupadas com a coisa pública quando em virtude de crises econômicas.

O que se tem é a violação dos direitos humanos, por parte das empresas transnacionais, e uma crescente dificuldade de responsabilização jurídica destas empresas, parte em função da substituição da função normativa do Estado pela regulação privada (ZUBIZARRETA, 2009).

A violação dos direitos humanos está relacionada com a máxima capitalista do máximo benefício no menor tempo, unida com a ânsia do poder e da acumulação de riquezas (ZUBIZARRETA, 2009). Certo que suas atividades deveriam ser pautadas pelo respeito aos direitos, contudo o Estado Fragmentado não tem folego para tratar dessas situações.

Neste contexto, a fraqueza dos sistemas jurídicos nacionais e internacionais, com maior ou menor intensidade reflete em um alto grau de impunidade das empresas transnacionais, que pode se estender para regiões ou países inteiros. As empresas transnacionais acabam se tornando verdadeiros espaços onde os direitos de homens e mulheres, fundamentalmente trabalhadores, não existem.

A impunidade é expressa em várias formas de violação que vão desde a promoção de guerras de agressão e conflitos interétnicos, para controlar recursos econômicos e aumentar a indústria bélica até a violações gerais de direitos humanos e trabalhistas, demonstrado pelos 
Jéssica Cindy Kempfer

índices de trabalho infantil, de trabalho em condições análogas à de escravo, de trabalho forçado e até mesmo de negação dos direitos dos povos (ZUBIZARRETA, 2009).

Os direitos humanos se transformam no desafio do século que é ao mesmo tempo teórico e prático. Tem-se tentado formular juridicamente uma base mínima de direitos que alcance todos os indivíduos e formas de vida que compõe a abstrata ideia de humanidade.

De um modo continuo continua-se assistindo durante as últimas décadas à substituição dos direitos obtidos por aquilo que se denomina de liberdades de mercado. Em definitivo, entramos num contexto em que a extensão e a generalização do mercado fazem com que os direitos comecem a ser considerados como custos sociais das empresas (FLORES, 2009).

As normas de comércio e inversões e as instituições que as ratificam e modificam, reinterpretam e adequam os contornos centrais dos ordenamentos jurídicos aos interesses das empresas transnacionais. Interesses públicos, coletivos e privados se compõem de modo variado, convergido ou divergido em relação às posições de força contratual para as contrapartidas oferecidas.

Apesar da importância das normas que buscam garantir a efetividade dos direitos humanos no âmbito internacional, não se pode esperar que efetivamente as normas nos deem todas as respostas. A segurança jurídica necessária é um princípio que não é só vinculado aos valores econômicos e sim com a própria soberania do Estado.

Existe a necessidade de modificar as relações sociais, a lógica de produção e de distribuição. A relação das empresa deve desde as questões políticas e as relações de poder. A partir de aqui as empresas e o Estado dever ser objeto de reflexão.

Para se pensar os direitos humanos hoje tem de se estar ciente dos processos históricos, mas comprometido com os desafios do seu tempo, assim como do Direito Global, suas instituições e seus atores. Afinal, não há sentido a manutenção espacial do ideal Direitos Humanos apenas nos territórios estatais ou, dos tratados internacionais vinculados originalmente aos Estados. 


\section{A AUTORREGULAÇÃO REGULADA}

No final do último século o desenvolvimento tecnológico faz crescer a integração e a velocidade da circulação de informações pelo planeta, dando impulso ao processo de globalização, o que gera pressão sobre a necessidade de desregulamentação da atividade econômica, em busca da livre circulação de recursos e mercadorias. Com isso a atividade privada passa a se autorregular.

Criam-se os códigos de ética e conduta de submissão e confecção voluntária pelas empresas que podem contes, simplesmente, uma enumeração de valores. Neste caso, a empresa manifesta seu compromisso com um conjunto de princípio aceitos com caráter geral, como por exemplo, a proteção dos trabalhadores.

Os códigos de ética que são frutos da autorregulação são aprovados por sujeitos privados, normalmente empresas e associações profissionais. Assim, os destinatários dos códigos são os mesmos que participaram de sua elaboração e por isso eles possuem um grau de vinculação variável. Podem estar articulados como instrumentos indicativos de condutas a serem seguidas como podem sancionar pelo seu descumprimento (GARDELLA, 2005).

Em virtude disso e após diversas crises econômicas, começa a ganhar força a tese de defesa da importância da necessidade da intervenção e da regulação estatal na economia. Contudo o Estado, por si só, se mostra incapaz de regular eficientemente todas as atividades empresariais.

É o que se convém chamar de autorregulação regulada, que é caracterizada pela intervenção dos entes privados no processo de regulação, de forma subordinada aos fins de interesse público estabelecidos pelo Estado. Este, titular do direito de regular, recorre às empresas para que colaborem com a elaboração de normas estatal na economia.

Essa nova forma de autorregulação responde a uma nova estratégia reguladora do Estado que colide frontalmente com as técnicas tradicionais, na medida em que seu trunfo é encontrar analogias e pontos de contato entre a autorregulação (privada) e a regulação (pública). É uma atividade privada de produção e controle de normas que se encontra 
condicionada por uma atividade pública tendente ao estabelecimento dos canais e dos controles aos quais se deve submeter a autorregulação (GARDELLA, 2005).

Ela engloba uma diversidade de manifestações que se situam em um ponto intermediário entre a regulação pública de caráter tradicional e autorregulação livre. Se trataria de uma realidade situada na ligação entre dois círculos: o público e o privado que, paulatinamente, aumentam seus pontos de contato.

As diversas manifestações da autorregulação regulada incluem pois, uma ampla gama de ações que vão desde a fixação e o controle das normas por parte de seus destinatários até os atos que se confundem com o exercício privado das funções de regulamentação e controles. Se caracterizaria, assim, a autorregulação, por um lado, a atividade dos organismos de normatização e a atividade dos organismos de certificação e, por outro lado, o cumprimento voluntário por parte das empresas das normas técnicas e a autocertificação empresarial do cumprimento de tais normas (GARDELLA, 2005).

A regulação pública da autorregulação é uma nova forma de intervenção indireta que, sob as vestes de uma retirada do Estado, esconde níveis de intervenção historicamente desconhecidos. Inclui o estabelecimento de sistemas de controle, e, também, a fixação de normas que regulamentam os fins perseguidos pela autorregulação. Nesse ponto pode-se citar: as normas procedimentais aplicáveis a adoção dos instrumentos de autorregulação; as normas procedimentais aplicáveis a adoção de instrumentos de autorregulação; a composição dos organismos de autorregulação e os requisitos de capacidade técnica e imparcialidade exigíveis dos sujeitos que se autorregulam (GARDELLA, 2005).

Essa conexão entre público e privado seria mais exitosa para a regulação de setores complexos de amplitude global que fogem da capacidade de regulação provida tanto pelos Estados como pelo próprio setor privado: como as empresas transnacionais. Dessa forma se garantiria que uma série de normas e sistemas de controles privados venha acompanhada de garantias constitucionais que daria suporte a proteção efetiva dos direitos humanos.

Os atores privados transnacionais vem produzindo normas com autonomia relativa diante do Estado, formando um ordenamento jurídico sui generis (TEUBNER, 2003) para a 
consecução de seus objetivos comerciais, o que, muitas vezes, acaba ferindo alguns bens jurídicos como o meio ambiente, a saúde e a dignidade humana.

A autorregulação que se quer é aquela suscetível de cobrir espaços onde há a necessidade de intervenção pública. Trata-se de uma autorregulação que aparece como contrapartida à desregulação. As normas e controles privados não só substituem a regulação estatal tradicional, mas também complementam as diversas técnicas de regulação de polícia (GARDELLA, 2005).

Lo relevante de este fenómeno es pues que, em la actualidad, la desintervención pública viene acompañada, significativamente, por la complementariedad o la sustitución, em primer lugar, de reglamentaciones públicas por reglamentaciones privadas - códigos de conducta, normas técnicas, protocolos y buenas prácticas -, que nos permitirían hablar de una autorregulación de carácter normativo, y em segundo lugar, de controles públicos por controles realizados por sujetos privados. [...] En primer lugar, la instrumentalización pública de la autorregulación permite superar el déficit de ejecución de la legislación estatal -y comunitaria- y el déficit de ejecución de las decisiones de la Administración pública. En segundo lugar, y como consecuencia de este déficit de ejecución de las decisiones públicas, la autorregulación aparece como la técnica más efectiva de la que dispone el Estado, en la actualidad, para cumplir su función como garante de algunos de los bienes más valiosos para la sociedad -el medio ambiente, la salud, la seguridad, la dignidad humana y el desarrollo de los menores-. En tercer lugar, el fomento y la imposición pública de la autorregulación permite establecer una correspondencia adecuada entre los responsables directos de las agresiones contra tales bienes -las empresas, la ciencia, la técnica o los medios de comunicación- y las medidas concretas para garantizar su protección. $Y$, en cuarto lugar, se evidencia también que los instrumentos de autorregulación poseen un nivel de armonización a nivel internacional que no es predicable de las normas y de los controles públicos. (GARDELLA, 2005, p. 78).

Necessário reconsiderar a ideia de eficiência das condutas normativas. Por um lado não se pode esperar que o Estado possa organizar e regulamentar todas as possibilidades de conduta. Por outro, não tem se mostrado acertado continuar com a lógica de autorregulação das organizações transnacionais.

Uma opção de normatividade que consiga mesclar o que pode ser considerado como bem sucedido em um tipo de ordem com outra pode levar a aprendizados intersistêmicos interessante, bem como a "possibilidades maiores de reprodução bem sucedida tanto das organização transnacionais quanto dos estado no tempo e no espaço.” (FORNASIER, 2015) 
Jéssica Cindy Kempfer

A técnica da autorregulação regulada se mostraria como uma estratégia estatal que daria efeitos público e uma imposição vinculante a autorregulação de uma forma que minimizaria a afetação dos bens coletivos por alguns agentes transnacionais Se asseguraria ao Estado a capacidade de sancionar condutas desviadas das normas objeto da autorregulação, garantindo aos membros da empresa, aos funcionários e ao coletivo, a atuação de acordo com a ética empresarial e, consequentemente, com a proteção dos direitos humanos.

Caberia ao poder estatal regular o contexto da autorregulação, estabelecendo cláusulas, requisitos e procedimentos pelos quais deve se desenvolver a autorregulação para gerar efeitos públicos. Por exemplo, a adoção de procedimentos transparentes pelos agentes privados.

Teoricamente, a autorregulação regulada possibilita que padrões não uniformes assegurem maior proteção formal e material aos procedimentos do que qualquer padrão uniforme e, consequentemente, mais rigoroso. A segurança no cumprimento de uma obrigação pode ser melhor assegurada por padrões não uniformes. Sendo assim, a não uniformidade na autorregulação regulada poderia ser uma vantagem. De certa forma, os acordos de proteção ambiental já aceitam esse princípio, exigindo controles de emissões mais rigorosos em países desenvolvidos do que naqueles em desenvolvimento. Portanto, a principal função do governo seria a de inspecionar, de garantir a independência deste grupo interno de conformidade e auditar sua eficiência e tenacidade.

How can enforced self-regulation resolve this dilemma? Each company would be required to write its own accounting rules in consultation with shareholders and other appropriate stakeholders (perhaps unions, perhaps the Defense Department for a major defense contractor). These rules should enable the company to meet its operational requirements while ensuring public accountability and acceptable comparability with the accounts of other companies. Once these rules have been ratified by the appropriate agency and made available to investors, any violation of them would, by definition, constitute an unacceptable accounting practice and be punishable by law. Tying the specificity of the rules to the unique circumstances of the company for which they were written renders fairness in accounts enforceable. Specificity can replace blandness without the overspecification for the majority of firms inherent in universalistic standards. In addition to the familiar practice of holding outside audits, internal audit groups would be mandated. Enforced selfregulation might, therefore, produce simple specific rules that would make possible both more efficient, comparable accounting and easier conviction of violators. (AYRES, BRAITHWAITE, 1992. p. 109) 
A abdicação da responsabilidade das empresas poderia ser minimizada pela participação conjunta entre empresas, governos e partes interessadas em um programa de regulamentação. Quando a empresa ajuda na composição das normas a ela aplicadas, é mais difícil que racionalize a ilegalidade. Além disso, evidências consideráveis indicam que a participação em um processo de tomada de decisão aumenta a aceitação e melhora a execução das decisões tomadas (AYRES, BRAITHWAITE, 1992. p.115).

As relações entre autoridade pública e privada são complexas. Nos casos de autorregulação regulada, está-se diante de uma nova abordagem que nos desafia a analisar esta nova estratégia e avaliar o seu papel na integração.

\section{CONCLUSÃO}

Com a globalização o comércio deixa de ser local a passa a ser global. As empresas deixam de ter suas fronteiras dentro de um estado para atuar em todo mundo e vem, de forma progressiva, substituindo o Estado como ator principal.

Os atores privados transnacionais modificam a capacidade normativa do Estado levantam questões sobre a governança nos processos econômicos globais. Os sistemas autorregulados oferecem uma resposta normativa mais rápida do que àquelas apresentadas na lógica da soberania estatal, contudo, também levantam questões atinentes aos direitos humanos que passam a ser regulados e negociados em sede contratual.

A cidadania tem sido substituída por consumidores; as normas públicas por acordos privados e o desenvolvimento humano pelas preferências de mercado. A ética empresarial está vinculada com o aumento dos benefícios para as empresas, onde o objetivo é a busca de preços competitivos.

Dessa forma, não há como se pensar em comércio global sem mensurar suas consequências humanas. O que sem visto é uma progressão geométrica da violação dos direitos humanos e da dificuldade de responsabilização das empresas. 
A autorregulação e a regulação não conseguem solucionar os problemas atinentes à globalização econômica. Nisso ganha forma a tese da autorregulação regulada, onde a intervenção dos entes privados no processo de regulação, de forma subordinada aos fins de interesse público estabelecidos pelo Estado.

Não se pode esperar que o Estado possa organizar e regulamentar todas as possibilidades de conduta, da mesma forma a lógica de autorregulação não se mostra a melhor opção. Assim, a Uma opção de uma normatividade intersistêmica pode levar a reprodução bem sucedida tanto das organizações transnacionais como do estado.

Essa conexão entre público e privado seria mais exitosa para a regulação de setores complexos e garantiria que uma série de sistemas privados fossem acompanhados de garantias constitucionais, que dariam suporte a efetiva proteção dos direitos humanos e minimizando a afetação dos bens coletivos por agentes transnacionais. 


\section{REFERÊNCIAS}

AYRES, Ian; BRAITHWAITE, John; Responsive Regulation: Trancending the Deregulation Debate. New York: Oxford. Oxford University Press. 1992.

BAPTISTA, Luiz Olavo. Empresa Transnacional e Direito. São Paulo: Editora Revista dos Tribunais, 1987.

BECK, Ulrich. O que é Globalização? Equívocos do globalismo: respostas à globalização/ Ulrich Beck; tradução de André Carone. - São Paulo: Paz e Terra, 1999.

CASSESE, Sabino. Oltre lo Stato. Bari/Roma: Laterza, 2006.

CRUZ, Paulo Márcio. Da soberania à transnacionalidade: democracia, direito e estado do século XXI: seleção e organização dos capítulos Emanuela Cristina Andrade Lacerda. Itajaí: Universidade do Vale do Itajaí. 2011

FARIA, José Eduardo. O direito na economia globalizada. $1^{\mathrm{a}}$ edição, $4^{\mathrm{a}}$ tiragem. Malheiros Editores Ltda. São Paulo, 2004.

FLORES, Joaquín Herrera. A reinvenção dos direitos humanos. Tradução de: Carlos Roberto Diogo Garcia; Antônio Henrique Graciano Suxberger; Jefferson Aparecido Dias. Florianópolis: Fundação Boiteux, 2009.

FORNASIER, Mateus de Oliveira; FERREIRA, Luciano Vaz. A autorregulação e direito global: os novos fenômenos jurídicos não-Estatais. In: Revista do Programa de PósGraduação em Direito da UFC, vol. 35.2, jul./dez. de 2015.

GARDELLA, Mercé Darnaculleta. Autorregulación y derecho público : La autorregulación regulada. Madri: Marcial Pons. 2005.

SASSEN, Saskia. Sociologia da Globalização; tradução Ronaldo Cataldo Costa; revisão técnica Guilherme G. de E. Xavier Sobrinho - Porto Alegre: Artmed, 2010.

SASSEN, Saskia. Territorio, autoridad y derechos. De los ensamblajes medievales a los ensamblajes globales. Buenos Aires: Katz, 2015.

SASSEN, Saskia. Territory, authority, rights: from medieval to global assemblages.

Princeton University Press, 2006.

STAFFEN, Márcio Ricardo. Interfaces do direito global. Rio de Janeiro: Lumen Juris, 2015.

TEUBNER, Gunther. A Bukowina Global: sobre a emergência de um pluralismo jurídico transnacional. In: Impulso: Revista de Ciências Sociais e Humanas, vol. 14, nº 33. Piracicaba: UNIMEP, janeiro/abril de 2003.

VARELLA, Marcelo Dias. Internacionalização do direito: Direito internacional, globalização e complexidade. Brasília: UniCEUB, 2013.

VIVIANI, Maury Roberto. Constitucionalismo global: crítica em face da realidade das relações internacionais no cenário de uma nova ordem mundial. Rio de Janeiro: Lumen Juris, 2014. 
Jéssica Cindy Kempfer

ZUBIZARRETA, Juan Hernández. Las empresas transnacionales frente a los derechos humanos: história de una asimetría normativa. Bilbao: Hegoa, 2009.

ZOLO, Danilo. Globalização: Um Mapa dos Problemas. Florianópolis: Conceito Editorial, 2010. 